\title{
Falando sobre superdotação na infância e adolescência
}

\author{
Simone Clemens \\ Especialista em superdotação na infância e adolescência pela IFWL \\ (Instituto de aprendizado integrado e terapias educacionais)/Alemanha \\ Pedagoga Montessoriana pela Associação Montessoriana de Aachen/ Alemanha \\ filiada a AMI, Associação Internacional Montessori \\ Pianista e professora de piano erudito (Instituto de Artes da UNESP \\ classe de elite do Professor e pianista Pietro Maranca) \\ $\square \underline{\text { simonecbc@gmx.net }}$
}

Recebido em 9 de junho de 2016

Aceito em 22 de setembro de 2016

Superdotação é uma característica inata do indivíduo; um potencial emocionalcognitivo muito acima da média que pode abranger uma ou mais áreas do conhecimento humano.

Quando falamos sobre superdotação falamos de uma característica inata, que faz parte deste indivíduo em questão. Sendo assim, esta característica não se adquire, muito menos se perde. Assim como não se perde a cor dos olhos ou o tipo de estrutura do cabelo. Não é possível treinar uma criança a ponto de chegar a ser superdotada. Pois se assim fosse, não estaríamos falando do fenômeno superdotação. Quando usamos este termo específico, estamos falando destas pessoas que já nasceram com este tipo de potencial, que já vieram ao berço com este presente da natureza (daí o termo usado em inglês - giftet Children). Este potencial não se adquire nem se perde, mas pode, deve e precisa ser desenvolvido. Este presente da natureza precisa de ajuda para ser desempacotado. Necessita da ajuda do próprio superdotado, da família, da escola, do meio ambiente e de toda a sociedade que o cerca.

Portador de altas habilidades é outro termo usado no Brasil. Ser superdotado ou ser portador de altas habilidades significa o mesmo, ou seja, trata-se do mesmo fenômeno!

A pessoa pode ser superdotada (ou possuir altas habilidades) em uma ou mais áreas. Os pesquisadores a fim de facilitar o entendimento do fenômeno, classificaram estas áreas em 4 grandes grupos: Talento intelectual, artístico, esportivo e social. 
Aqui é possível todas as combinações. Exemplo: a pessoa pode ser superdotada somente intelectualmente e ter um potencial normal médio nas outras áreas; ou a pessoa pode ser superdotada intelectualmente, artisticamente e socialmente e ter uma capacidade normal média para esporte. Ou ela pode ser superdotada em todas as quatro áreas e assim por diante. Como disse, todas as combinações são possíveis.

Superdotação não é um fenômeno novo, de moda. Muito menos algo que foi descoberto agora. É um fenômeno inerente à natureza, que sempre foi observado pelo ser humano. Vemos que com o desenvolvimento da ciência e tecnologia, este vem sendo mais objetivamente pesquisado, documentado e muito mais conhecido pela sociedade. Antes a superdotação era mais vista como mistério, dom divino, algo sagrado ou nebuloso, o qual não se adiantava procurar explicação. Já hoje, com o avanço da psicologia, neurologia, máquinas que permitem observar o funcionamento do cérebro, o estudo do fenômeno está saindo do âmbito da abstração e passando para a pesquisa científica.

É verdade que ainda não se sabe ao certo como se dá o processo do fenômeno. Por exemplo, não se tem a certeza se é genético ou não, embora este apareça em muitos casos em uma mesma família. A superdotação assim como ela pode permanece em várias gerações, também pode desaparecer da família ou mudar de área muito bruscamente. Por exemplo: se a mãe tem talento artístico, o filho pode ser também superdotado, porém intelectualmente. Como se dá esta variação? Não sabemos. Também há vertentes que pesquisam se o fenômeno é passado pelo cromossomo $\mathrm{x}$ de mãe para filhos, já que muitos casos se observa desta linha. Uma prova ainda não foi possível. A pesquisa do fenômeno continua interessante e fascinante.

\section{MAS COMO SABEMOS QUANDO UMA CRIANÇA NASCE COM ESTE PRESENTE?}

A resposta não é tão fácil para olhos inexperientes. Mas para estudiosos no assunto não é tão difícil. Já se sabe um bom bocado sobre a questão. Sabemos por exemplo, que o fenômeno não se caracteriza isoladamente, mas sim é formado de um conjunto de determinadas características combinadas.

Alguns destes pontos são: 
- Curiosidade muito acentuada de conhecer o mundo;

- Menos necessidade de sono que a maioria das crianças;

- Alta capacidade de concentração;

- Vocabulário vasto e rebuscado para a idade;

- Pouco prazer em atividades repetitivas, de automatização;

- Alto senso ético, de justiça;

- Memória muito acima da média;

- Aguçado senso de humor;

- Sensibilidade muito aflorada;

- Interesse por temas complexos, pouco comuns para a idade;

- Tendência ao perfeccionismo;

- Alta capacidade de reflexão para relações de causa e efeito;

- Ideias e soluções inovativas ou pouco comuns.

A maioria das crianças superdotadas não possuem todas estas caraterísticas, mas uma combinação delas.

Ao ler os pontos acima citados, não parece muito difícil detectar um superdotado. Mas as aparências enganam. A prática mostra que a dificuldade está em entender como se mostra cada ítem acima citado.

Por exemplo: como se mostra no cotidiano uma memória muito acima da média em uma criança superdotada? Como se diferencia no ponto memória, a criança superdotada da não superdotada na primeira infância?

Para os pais a dificuldade maior apresenta-se quando a criança é seu primeiro filho. Neste caso há a falta de comparação. Já para os educadores a dificuldade pode estar no tempo curto que eles passam com a criança; eles vêm a criança somente no ambiente 
escolar e tem que dividir sua atenção com muitas outras crianças. O sistema de ensino tradicional atual também não tem seu ponto forte na observação individual de cada criança, como é no sistema Montessori de ensino por exemplo.

Embora o processo de memória continue sendo muito individual, conseguimos observar alguns pontos fixos. Por exemplo: a criança superdotada até os 5 anos mostra uma memória mais espontânea. Ela memoriza o que lê, o que houve sem pensar muito se aquilo vai ser útil a ela ou não, se é de seu interesse ou não. Muitas vezes até sem muito controle sobre o processo, "sem querer". É comum vermos entre estas crianças os seguintes exemplos:

- A criança leu um livrinho sozinha. (Lembrem-se que muitas crianças superdotadas já leem bem aos 5 anos de idade). A mãe pergunta se o livro foi bom, se ela gostou e ao conversar sobre o livro, a mãe faz alguma pergunta objetiva sobre a história lida: “E a Mariazinha conseguiu achar o caminho de casa? " Ao invés da criança responder objetivamente sim ou não, ela cita o parágrafo ou até a página inteira ao pé da letra onde contém a resposta para a pergunta. “ João estava em casa esperando sua irmã, quando de repente ao ouvir a porta se abrir, João se depara com Mariazinha que chega feliz e contente..."

Ou seja, a criança memorizou, citou o trecho onde estava a resposta. Como exatamente se dá este processo é difícil saber, pois a criança mesmo, ainda não sabe explicar e nem domina o que acontece com ela. Talvez seja uma memória fotográfica, já que muitas fecham os olhos quando dão a resposta. Já outras precisam de silêncio para achar o trecho, memória auditiva interna? É fascinante. Já se pedirmos para esta mesma criança citar o livro inteiro, de acordo com a minha experiência, ela vai dizer que não sabe. Ou seja, ela ainda não coordena, não tem o domínio sobre sua capacidade, ela se dá espontaneamente

- Outro exemplo de memória espontânea muito vista é a exemplo igreja. Muitas crianças na primeira infância acompanham seus pais `a igreja. Normalmente esta visita é um passeio bastante desinteressante para a esmagadora maioria delas. Enquanto seus pais prestam atenção ao que está sendo falado pelo padre/pastor, a criança está no tablet, lendo um livro ou simplesmente andando ou brincando aos 
redores dos bancos com outras crianças. Quando o culto acaba e a família vai para casa, é comum vermos esta mesma criança que aparentemente não prestou nem um minuto de atenção no que havia sido dito na igreja, de uma vez citar partes inteiras do que o padre falou, literalmente. É o mesmo fenômeno espontâneo citado no ponto acima.

- Crianças que decoram países com suas capitais, aprendem a contar em outros idiomas, sem que os pais as obriguem, mostram grande prazer com a sua capacidade de memorização. Esta também é uma característica forte de superdotação.

Já depois da primeira infância, parece que o processo de memorização do superdotado muda. Esta capacidade torna-se mais seletiva e objetiva de acordo com seus interesses no momento. A criança se foca em temas de seu interesse e consegue dispor da habilidade da sua memória privilegiada para estes pontos específicos. Já para atividade que não estão entre as preferidas, por exemplo matérias que estão sendo vistas na escola, ela não usa sua capacidade especial.

Então por exemplo, é possível que um superdotado saiba, tenha conhecimentos notáveis sobre a história do Egito antigo, o nome de todos os faraós, de quando a quando eles regeram, sobre a comida, o sistema de plantação, armazenamento de água, como eram construídas as pirâmides e não saiba os estados brasileiros com suas respectivas capitais que era para saber para a prova de ontem.

A criança nem sempre age assim propositalmente. Cientistas observam que para ser ativado o potencial, há que haver a combinação: potencial + motivação + interesse, juntamente com o apoio da família, amigos e escola (Modelo de Mönks e Ypenburg). Apoio familiar entende-se neste contexto como bom clima familiar e apoio da escola significa muito resumidamente pelo menos uma boa relação com o professor e colegas de sala de aula.

A grande dificuldade do professor aqui, é com certeza, não ter na sua formação profissional o tema superdotação. Ele então não consegue reconhecer e nem entender este aluno e ainda duvidando de suas capacidades. Se este aluno é tão inteligente como dizem e tem tão boa memória, porque ele não escreve notas excelentes nas minhas provas? 
Com este exemplo clássico da memória, fica claro que cada item entre os pontos acima citados das características gerais dos superdotados, tem que ser observados e analisados a fim de que uma criança superdotada ser reconhecida como tal. Por isso é difícil para o professor, educador sem uma formação adequada, reconhecê-los em sala de aula. Para os pais torna-se mais fácil reconhecê-las quando a criança superdotada não é o primeiro filho ou quando os pais mesmos são superdotados e vem suas características espelhadas na criança.

Os talentos artísticos e do esporte são os normalmente mais fáceis de serem reconhecidos. E além de serem mais fáceis de serem reconhecidos, também são mais fáceis de serem aceitos pela sociedade. A aceitação dos talentos artísticos já vem da nossa cultura de ver a arte como "dom divino". Já desde o classicismo e com o cúlmino no romantismo, as crianças prodígios, já tocavam, cantavam nos palácios para os membros da corte real, para príncipes, reis e rainhas...lembre-se do pequeno Mozart com sua irmã Nanerl com seu duo de piano e violino, onde viajaram toda sua infância pela Europa sendo admirados pelo seu talento.

Também no esporte, talvez herança da Grécia antiga, os atletas eram vistos como pessoas especiais, com dom especial.

Já o talento intelectual parece que incomoda na nossa sociedade, é visto como concorrência, sendo muitas vezes motivo de inveja. Porque e como isso se dá, deixo à cargo dos filósofos, antropólogos, sociólogos e historiadores.Como pedagoga, me atenho neste artigo ao âmbito da educação.

\section{UMA VEZ RECONHECIDOS, ACABAM-SE AS DIFICULDADES PARA O SUPERDOTADO?}

Infelizmente não. Uma vez reconhecidos, o superdotado continua precisando muito da ajuda da família e da escola. Na família é preciso que ele seja aceito. É preciso que o seu talento seja aceito, que a sua condição de superdotado seja aceita. Parece óbvio, mas não é.

Muitos pais sentem-se inseguros, incomodados com o fato do filho ser superdotado. As inseguranças mais comuns são: 
"Vou conseguir proporcionar para meu filho a educação especial que ele necessita materialmente? (Escola, cursos extras, etc)?" ou " Saberei como pai, responder todas as suas perguntas?" ou "Será que ele vai me amar e me respeitar mesmo eu não sendo tão inteligente como ele?" "O que dirão os amigos, os parentes, quando souberem que meu filho é superdotado? " ou "Porque meu filho não é normal como todos os outros? Tudo seria tão mais fácil!" "Eu não entendo deste tema de -superdotação-, agora vou ter que virar especialista neste assunto, o qual há pouco eu nunca havia nem ouvido falar?"

Todas estas inquietações passam pela cabeça pelo menos uma vez da maioria dos pais de crianças superdotadas. Enquanto os pais não tranquilizarem seu coração, não se sentirem bem, à vontade no seu novo papel de pais de uma criança com altas habilidades, a criança também não se sentirá bem. Pois todas as inseguranças, inquietudes dos pais, espelham-se direta ou indiretamente na criança.

Já na escola a problemática é outra. Educadores e professores como já disse acima, não são preparados na sua formação profissional para o fenômeno superdotação. Como consequência disso, primeiramente eles não sabem reconhecê-las. No jardim de infância/pré-escola onde a educadora tem um contato mais intenso com a criança, muitas delas até percebem que a criança é diferente, porém infelizmente na maioria das vezes, ela não chega à suspeita de superdotação.

$\mathrm{Na}$ escola é ainda mais difícil. Os professores estão mais sob pressão de metas curriculares, correções de provas, onde fica ainda mais difícil que eles reconheçam uma criança superdotada sem ter tido a devida formação para isso. Quando eles sabem que a criança é superdotada, por exemplo, quando a criança já vem com um diagnóstico, os professores se vêem numa situação constrangedora, pois não sabem como ajudar, como apoiar devidamente esta criança.

Além do preconceito e da crença em todos os clichés para com o tema. Cito aqui os conceitos errôneos mais comuns:

"Este aí é superdotado, não precisa de mim, aprende sozinho, vou prestar atenção no outro aluno que tem dificuldade" ou "Ele não é superdotado? Como não sabe isso?" ou "Essa coisa de superdotado não existe, isso é invenção destes pais modernos", "Coitada da criança, falam que ela é superdotada, mas ela não sabe nem escrever, olha esta caligrafia!" ou "Superdotado? Ele é sem 
educação, isso sim, me interrompe o tempo todo com estas perguntas, só pra ver se eu sei responder!"

E por aí em diante. Eu poderia escrever uma folha inteira de preconceitos e clichés que o professor não preparado tem para com estas crianças.

As consequências disso para a criança são catastróficas! Elas se caracterizam em um tédio constante, que pode levar desde uma grande frustração, ao desgosto pelo aprender, pela escola, até a perda da autoestima, à depressão e até ao suicídio.

Se fala muito sobre o lado social do superdotado, pela suposta incapacidade de ter amigos. Isto é um grande e antigo cliché. Muitos e longos estudos, que já acompanharam crianças superdotadas por uma vida toda, mostram que elas têm na sua maioria, uma capacidade social ainda mais aguçada do que a maioria das crianças. Quanto maior o grau de inteligência intelectual, maior a inteligência social! O cliché se baseia nas consequências, depois da criança superdotada ter vivido tantas más experiências na pré-escola e na escola, como o bullying por exemplo, que ela passa a fechar-se para as pessoas para poder protegerse.

Já as crianças que não passam por estas más experiências, mostram um enorme grau de socialização.

Por esta razão, me atenho ao problema do superdotado na família e principalmente na escola no que diz respeito às condições de aprendizado intelectual.

A família precisa de orientação de um profissional que a oriente sobre as características e as necessidades especiais do seu filho. Este profissional tem que entender sobre o tema superdotação, é claro. Ele pode ser um psicólogo, um psicopedagogo, um neuropsicólogo, um professor, um pai mais experiente, que já tenha tido um filho superdotado e melhor ainda um especialista em superdotação. Geralmente, as famílias procuram orientação mais cedo ou mais tarde. 0 problema maior está nas instituições de ensino mesmo.

A lei de obrigação ao apoio ao superdotado saiu em de 2015. Mas a lei tem que ser apoiada pela sociedade. Além da lei, há que haver a conscientização do dever de trabalho com o aluno superdotado. A criança com altas habilidades, necessita de um cuidado especial na escola, da atenção, do carinho, do reconhecimento, do respeito do professor tanto 
quanto todas as demais crianças também.

O educador e o professor necessitam da formação necessária para saber reconhecer e principalmente como ajudar este aluno em sala de aula. Os gestores mostrar-se-iam mais inteligentes, se apoiassem os educadores e professores neste caminho. Qual o gestor que não gostaria de ver sua instituição sendo apontada como exemplo de competência?

Bom trabalho, ser exemplo de excelência e competência traz mais alunos; muitos alunos trazem mais lucro; mais lucro pode trazer melhorias para a instituição, que mais uma vez gera bom comentários.... Enfim, um círculo virtuoso.

Deve-se investir em especializações para os professores, tratar o tema com seriedade, com vontade. Informar-se quais as possibilidades existentes para se apoiar alunos superdotados. Dentro destas existentes, qual delas seria viável na sua instituição? É difícil? Não, absolutamente não! Primeiramente é questão de estar sensibilizado com o tema e querer como pedagogo, como gestor, ajudar com país com uma educação de qualidade.

$\mathrm{Na}$ Alemanha usa-se carinhosamente o termo "cabeças inteligentes" para os superdotados. Cabecinhas estas que com a sua ajuda, levarão a humanidade a ideias novas, ao desenvolvimento da ciência, que inventarão máquinas maravilhosas, curas para doenças, trarão grande contribuição para a paz mundial. O Brasil e o mundo precisam ficar mais inteligente!

\section{REFERÊNCIAS BIBLIOGRÁFICAS}

GAMM, Rüdiger; EHLERT, Alexandra. Train your Brain Edit. Heiner, 2008.

MÄHLER, Bettina; HOFMANN, Gerlinde. Ist mein Kind hochbegabt? 5. Ed. Edit. RORORO, 2003.

TOLAN S., Stephanie, WEBB T. James, MECKSTROTH A., Elisabeth. Hochbegabte Kinder, ihre Eltern, ihre Lehrer. 5. Ed. Edit. Huber, 2007.

WITTMANN, Anna Julia; HOLLING, Heinz. Hochbegabtenberatung in der Praxis. 2. Ed. Edit. Hogrefe, 2004. 